\title{
CORRECTION
}

\section{Correction to: Design considerations of constructed wetlands to reduce landfill leachate contamination in tropical regions}

\author{
Yuka Ogata $^{1} \cdot$ Tomonori Ishigaki $^{1} \cdot$ Yoshitaka Ebie $^{1} \cdot$ Noppharit Sutthasil $^{2} \cdot$ Chayanid Witthayaphirom $^{2}$. \\ Chart Chiemchaisri ${ }^{2} \cdot$ Masato Yamada $^{1}$
}

Published online: 12 August 2018

(c) Springer Japan KK, part of Springer Nature 2018

\section{Correction to: \\ Journal of Material Cycles and Waste Management \\ https://doi.org/10.1007/s10163-018-0755-0}

In the original publication of the article, Eq. (5) was pub-

lished incorrectly. The correct equation is given below.

$R_{\text {pond }}(\%): \sum_{i=1}^{n}\left(\left[-E_{\text {pan }}+P_{i}-I\right] \times 10^{-3}+\frac{L G_{i}}{R_{\text {pond }} \times 10^{-2} \times A}\right) \leq D$

The original article has been corrected.

The original article can be found online at https://doi.org/10.1007/ s10163-018-0755-0.

Yuka Ogata

ogata.yuka@nies.go.jp

1 Center for Material Cycles and Waste Management

Research, National Institute for Environmental Studies, 16-2

Onogawa, Tsukuba, Ibaraki 305-8506, Japan

2 Department of Environmental Engineering, Faculty of Engineering, Kasetsart University, 50 Ngam Wong Wan Road, Lat Yao Chatuchak, Bangkok 10900, Thailand 